\title{
Penetrating Abdominal Trauma; an Overview of Recent Turmoil in Kashmir Valley
}

\section{Background}

We present a review article, an overview of abdominal trauma, Penetrating in nature that typically involves abdominal cavity by pellet guns, gunshot injury and tear gas shell injuries mostly. This article is in reference to the current crisis that cropped up in Kashmir being a Conflict Zone. The recent warfare resulted into different kinds of traumas; Which were received at our centre at government medical college, SMHS and its associated hospitals. Our hospital, situated in the centre of Kashmir, being a tertiary care hospital; major trauma centre is always apt to receive such traumas for management. The minor traumas were also received by different districts and sub district hospitals across the valley. The hospital is equipped with a well structured triage centre where patients are received at the first instance and the $\mathrm{ABC}$ of trauma is being instituted in the golden hour. We, at department of general surgery purely received abdominal traumas for further management .The current turmoil in Kashmir valley resulted in many deaths and different types of traumatic injuries like neurosurgical, musculoskeletal, orthopedic, ophthalmological, cardiovascular and on top of that abdominal trauma. The peculiarity of this kind of trauma was high preponderance of pellet injuries received by our department of ophthalmology ranging in thousands in figures which were managed by the concerned department. Next to that abdominal trauma was soon to rank on number two with bullets and pellets. However, we too received trauma injuries caused by other than the firearm and war weaponry gadgets. It is proper to mention here that a good number of cases were received by the department of surgery wherein the injuries were inflicted on the assailants by batons, physical torture, and stone pelting. Most of these injuries were not minor in nature and good number of them fell in the surgical intervention while as others were managed in the hospital for a long period by conservative management.

Keywords: Trauma; Abdomen; Penetrating

\section{Anatomy of Penetrating Abdominal Trauma}

The patients who were sent to the department of general surgery by Trauma triage unit were purely of abdominal nature for further management. The anatomical classification is important in guiding the Clinician's suspicion for specific organ injury. We received a mixed nature of blunt and penetrating abdominal injuries scattered to all the quadrants of the abdomen. The Intra peritoneal abdominal organs were among the worst hit by the war weaponry. Among the solid organs being injured like spleen, liver and also the hollow viscous organs, stomach, jejunum, ileum, transverse colon, and rectum were also involved. The injuries were like perforations of the gut, shattered splenic injury and liver lacerations.

\section{Pathophysiology of Trauma Injuries}

\section{Surgery}

\section{Mumtazdin Wani ${ }^{*}$, Mushtaq Chalkoo², Peer Hilal Ahmad Makhdoomi', Ankush Banotra', Mueed Yousuf Sofi' ${ }^{1}$, Yasir Arafat ${ }^{1}$ and Shakeeb ${ }^{1}$}

${ }^{\prime}$ Department of Surgery, Government Medical College, SMHS and Associated Hospitals, Srinagar, India

${ }^{2}$ Department of Surgery, Government Medical College, Srinagar, India

*Address for Correspondence

Mumtazdin Wani, Professor and Head, Department of Surgery, Government Medical College, SMHS and Associated Hospitals, Srinagar, Jammu and Kashmir, India, E-mail: drmumtazwani@gmail.com

Submission: 01 September, 2016

Accepted: 03 October, 2016

Published: 08 October, 2016

Copyright: (ㄷ) 2016 Wani M et al. This is an open access article distributed under the Creative Commons Attribution License, which permits unrestricted use, distribution, and reproduction in any medium, provided the original work is properly cited.

The injuries were caused by the different kinds of weapons used on the assailants. On analysis of the wounds; wounds of entry and exit, an Observation was inferred regarding the pathophysiology that must have gone into the cascade of trauma, the patients had received. The gun shot wave is caused by missile propelled by the combustion of powder. These wounds involve high energy transfer and consequently involve an Unpredictable pattern of injuries. Secondary missiles like bullets

and bone fragments can inflict additional damage. The weapons used seemed to have both military and hunting fire arms which have higher missile velocity than hand guns resulting in high energy transfer. The penetrating abdominal trauma due to gunshot wounds involves mostly the hollow viscera in descending order as follows:

Smallbowel

Large bowel

Solid organs like liver and spleen

and abdominal vascular structures [1].

The severity of short gun wounds depends upon distance of the victim from the weapon. The patients who were hit by pellets (Figures 1 and 2); the penetrating injuries of the viscera were minimal as its velocity decreases rapidly after the shell leaves the barrel of the gun. When the distance is less than 3 yards the injury is considered as high velocity if the distance exceeds 7 yards most of the buckshot only penetrates the subcutaneous tissue. In this reference we saw the mixed pattern of such injuries that were managed conservatively and the ones with high velocity injuries were taken for operative management. The wounds that resulted into the blunt trauma caused by other than missiles were also grievous in nature however not typically penetrating yet impalement injuries were found in few (Figures 3 and 4).

\section{Etiology of Penetrating Abdominal Trauma}

Gunshot wounds are considered as high velocity projectiles and the most common cause of penetrating abdominal trauma; 


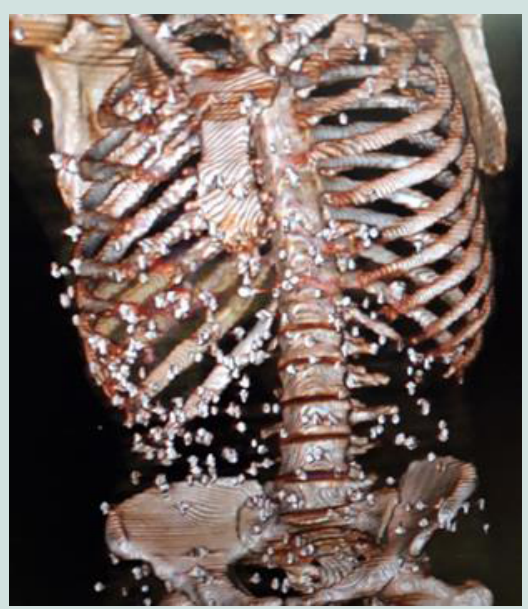

Figure 1: Pellets on CT abdomen.

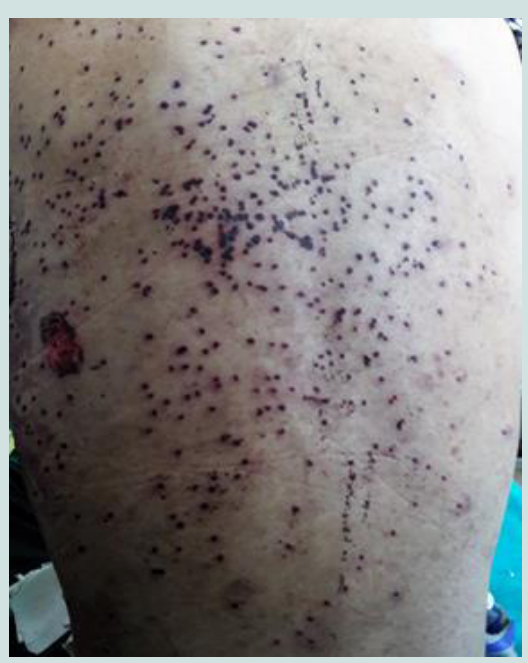

Figure 2: Multiple pellets back.

$65 \%$ followed by stab wounds $31 \%$ shot gun wounds, $5 \%$, penetrating abdominal trauma results from urban violence. Domestic violence crosses all socioeconomic barriers and is an important consideration in the evaluation of injuries sustained at home. From the global perspective, penetrating trauma results principally from military actions and warfare. However penetrating abdominal trauma may also be iatrogenically produced. Documented complications of diagnostic peritoneal lavage injuries to the underlying bowel, bladder or major vessels like aorta and vena cava are known. The trocar injuries in minimal access surgeries have also been reported and published.

\section{Epidemiology}

\section{International statistics}

The firearm mortality rates across the world vary widely from 0.05 in Japan to 14.24 in United States. Firearm associated homicide mortality was highest in Mexico at 10.35; firearm associated Suicide was highest in unites states at 6.3. The frequency of penetrating abdominal injury across the globe relates to the industrialization of developing nations, weapons available and significantly to the presence of military conflicts therefore frequency varies from place to place.

\section{Racial differences in incidence}

Although quantifying the death rate for penetrating abdominal trauma by race is difficult, the relative risk of death from penetrating injury in general in know African-American males have a 3 fold increase in relative risk of death compared with their white male counterparts [2]. African-American females have a 2.5 fold increase in relative risk of death compared with their white female counterparts. The Indian scenario of trauma is growing with the development and urbanization of the rural India. All trauma data from India primarily emanates out of road traffic injury. A vehicular accident is reported every 2 minutes and death every 2 minutes on Indian roads. The majority of fatal road accident victims are pedestrians, two wheeler drivers and bicyclists. The trauma and injury is major blow to our economy. India being a developing country, the selective reference for the incidence and statistics for the selective warfare and the terrorist attacks is not available in the literature. In Kashmir being a conflict zone reports the surges in the violence warfare and subsequently the trauma victims. According to a current survey published the literature fatalities in terrorist violence 1988-

2014 in Jammu and Kashmir SATP (south Asian terrorism portal) reports a high surge of trauma victims during 1995 upheaval and also in 2001. There has been a gradual increase in the terrorist activities from 2001-2016. The total fatalities in terrorist violence reported by the data till August 14, 2016 are 44019 including the civilians, security forces and terrorists SATP (South Asian Terrorism portal). It is pertinent to mention here that countries like Yemen and Syria too are involved in terrorist attacks and warfare injuries and more mortality is reported from both countries from ISIS attacks. The children mortality is peculiar about their deaths.

\section{Prognosis}

The death rate from penetrating abdominal trauma depends on extent of injury. The Patients with anterior abdominal wall injuries

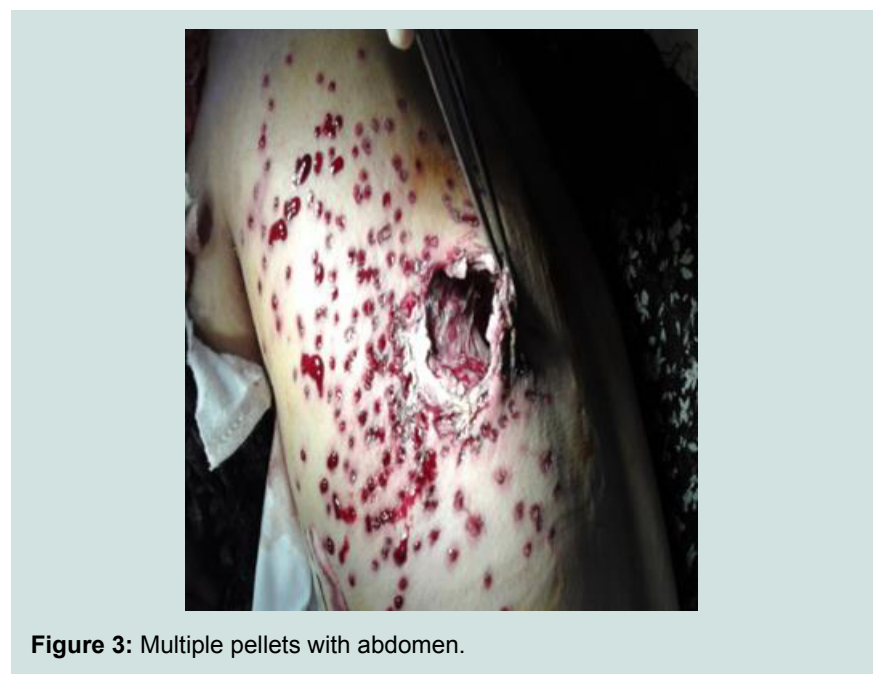




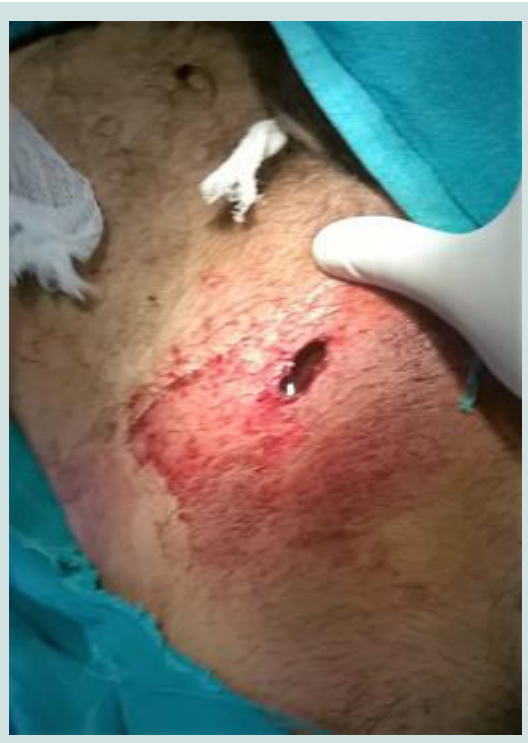

Figure 4: Exit wound bullet injury entry wound.

without peritoneal injury have a zero percent mortality rate and minimal morbidity rate. An average mortality rate for all patients with penetrating abdominal trauma is approximately $5 \%$ in most level 1 trauma centers. The survival from penetrating abdominal trauma has not changed in the past decade largely because of deaths within 24 hours resulting from irreversible hemorrhagic shock and exsanguinations. More than $80 \%$ of deaths occur within 24 hours of admission, $66.7 \%$ at the initial operation associated with abdominal vascular injury. However survival from penetrating abdominal injury without vascular injury is high. The temporal distribution of deaths in penetrating trauma is significantly different than that of blunt trauma. The majority of death from penetrating trauma occur between 1 and 6 hour from admission while as deaths due to blunt trauma occur beyond 72 hours and the lowest occur within the first hour [3]. The general factors that predict a mortality from penetrating abdominal trauma include the following; female sex, long interval between injury and

operation, presence of shock on admission, coexisting cranial injury. Death rate is markedly influenced by prehospital hypotension, massive hemorrhage, arrest in the field or on presentation, acidosis with an initial $\mathrm{pH}<7$, lactate levels $>20$ mmoles/lt, and base deficit more negative than 15 meq $\mathrm{Hco}_{3}$ [3]. In a series by Nicholas and colleagues of 250 patients with penetrating abdominal trauma and positive laparotomies the overall survival was $86.8 \%$ [4]. Mortality was found to be associated with the number of organs injured, vascular injury, the need for damage control surgery, emergency department thoracotomy. The damage control surgery has been used with some success in the management of patients with extensive abdominal trauma, it's associated with significant morbidity, including sepsis intra-abdominal abscess or gastrointestinal fistulas according to Nicholas et al. [5]. It is important to note that the patients who present in the emergency department in the early postoperative period with abdominal pain and signs of infection should be strongly considered for CT scan and surgical consideration. Injury patterns differ depending on the weapon. Low velocity stab wounds are generally destructive and have a lower degree of mortality and morbidity than gunshot wounds and shot gun blasts. However gunshot wound and other projectile have a higher degree of velocity and produce fragmentation and cavitations' and results in higher morbidity [5].

\section{Patient education}

It is important to educate the patient family and the support system if the medical community wishes to proactively reduce the incidence of violent injuries in our society, that way health care providers are integral part of reducing the violence in the society. An overall survey of our patients in current turmoil in Kashmir valley has explored a newer horizon of presentations of trauma victims. We observed that the pellet injuries do not only cause morbidity but mortality too.

\section{References}

1. Feliciano DV, Rozcyki GS (1995) The management of penetrating abdominal trauma. Adv Surg 28: 1-39.

2. Haider $\mathrm{AH}$, Chang DC, Efron DT, Haut ER, Crandall M, et al. (2008) Race and insurance status as risk factors for trauma mortality. Arch Surg 143: 945-949.

3. Demetriades D, Murray J, Charalambides K, Alo K, Velmahos G, et al. (2004) Trauma fatalities: time and location of hospital deaths. J Am Coll Surg 198: 20-26.

4. Moore EE, Feliciano DV, Mattox KL (2004) Trauma, 5th. Injury severity scoring. McGraw-Hill, USA, pp. 88

5. Nicholas JM, Rix EP, Easley KA, Feliciano DV, Cava RA, et al. (2003) Changing patterns in the management of penetrating abdominal trauma: the more things change, the more they stay the same. J Trauma 55: 1095-1108. 